\title{
The Spread of a Released Clone of Gibberella zeae from Different Amounts of Infested Corn Residue
}

Melissa D. Keller, Department of Plant Pathology, Physiology, and Weed Science, Wade E. Thomason, Department of Crop and Soil Environmental Sciences, and David G. Schmale, III, Department of Plant Pathology, Physiology, and Weed Science, Virginia Tech, Blacksburg 24061

\begin{abstract}
Keller, M. D., Thomason, W. E., and Schmale, D. G., III. 2011. The spread of a released clone of Gibberella zeae from different amounts of infested corn residue. Plant Dis. 95:1458-1464.

Corn residue is a significant source of inoculum for epidemics of Fusarium head blight (FHB) in wheat and barley, but little is known about the influence of different amounts of corn residue on FHB. We monitored the spread of a released clone of Gibberella zeae (Fusarium graminearum), causal agent of FHB, from small 0.84-m-diameter research plots containing 45,200, or $410 \mathrm{~g}$ of infested corn stalk pieces in winter wheat and barley fields in Virginia over 3 years (2008 to 2010). The fungus was recaptured through the collection of wheat and barley spikes at 0 and $3 \mathrm{~m}$ from the source and the released clone was identified in heterogeneous background populations using amplified

fragment length polymorphisms. Results showed a slightly greater intensity of recovery of the clone at a greater distance when more infested residue was present. Plots containing larger amounts of inoculum $(410 \mathrm{~g})$ generally resulted in a smaller decline of recovery of the clone at $3 \mathrm{~m}$ from the source, indicating a greater spread from the larger inoculum source. The clone was also recovered at distances $\geq 18 \mathrm{~m}$ from inoculum sources. Larger amounts of corn residue generally had less influence on clone recovery in plots containing a moderately resistant wheat cultivar than those containing a susceptible wheat cultivar.
\end{abstract}

Fusarium head blight (FHB) has been recognized in North America for over 100 years (37). It is one of the most economically important diseases of wheat and barley (43) and continues to impact areas where conditions are environmentally favorable to the pathogen. FHB is primarily caused by Gibberella zeae (Schwein.) Petch (anamorph: Fusarium graminearum sensu stricto Schwabe) in the United States $(27,40)$. A mycotoxin known as deoxynivalenol (DON) may be produced by the fungus in the infected grain. The United States Food and Drug Administration's recommended tolerance levels for DON are $1 \mathrm{ppm}$ in finished food products for human consumption and are variable for grain or grain by-products for animal consumption, depending upon the type of animal (2). Adverse health effects are possible for humans $(34,35)$ and domestic animals (33) if contaminated grain is consumed.

G. zeae survives saprophytically on wheat, barley, and corn residues, all three of which are regarded as primary inoculum sources for FHB epidemics $(31,37,40)$. Perithecia form on corn residue and, in the late spring and early summer, release ascospores that can be deposited on wheat and barley spikes. If environmental conditions are favorable (i.e., high relative humidity and frequent rainfall; 15,27,32), infection can occur from the time of anthesis and possibly through grain fill $(9,10)$. Infected seed may appear

Corresponding author: D. G. Schmale, III, E-mail: dschmale@vt.edu

This research was supported in part by grants to D. Schmale from the Virginia Small Grains Board (proposal numbers 08-2554-06 and 09-3003-06) and the U.S. Wheat \& Barley Scab Initiative of the United States Department of Agriculture (agreement number 59-0790-7-078). Any opinions, findings, conclusions, or recommendations expressed in this publication are those of the authors and do not necessarily reflect the view of the Virginia Small Grains Board or the United States Department of Agriculture.

* The $\boldsymbol{e}$-Xtra logo stands for "electronic extra" and indicates that Figure 1 appears in color in the online edition.

Accepted for publication 29 June 2011.

doi:10.1094/PDIS-03-11-0218

(C) 2011 The American Phytopathological Society smaller than normal, white or pink, and wrinkled, and may contain high levels of DON, all of which may affect marketability of infected grain (27).

Previous research has investigated the role of corn residue remaining on the soil surface prior to the planting of wheat or barley and its impact on FHB infection. Dill-Macky and Jones (14) found lower FHB incidence and severity with tillage treatments involving a moldboard plough to minimize residue than in those using a chisel plough or no tillage implement. They also found that wheat planted after corn showed the highest FHB infection when compared with wheat planted after soybean (14).

Nita et al. (29) evaluated FHB disease incidence, FHB severity, and DON concentration from field experiments in 2003 and 2004. The risk of FHB increased with greater concentrations of inoculum from within-field sources when environmental conditions were moderately favorable for disease. In both greenhouse and field experiments, Stein et al. (39) found that disease incidence and severity increased with an increasing number of $G$. zeae conidia applied. DON levels also were found to be positively related to inoculum concentration. Although the mathematical functions attempted were not as clearly defined for the field conditions, results accurately predicted the potential for FHB infection in moderate epidemic seasons (39).

Reduced-tillage practices have been used to minimize soil erosion and moisture loss for the past 25 years (27). Corn residue remaining in a no-till or minimal-till system may provide overwintering sites for G. zeae. With the increase of corn production due to incentives for ethanol-based fuel and as an alternative crop to small grains in FHB-prone regions (13), overwintering sites for G. zeae on corn residue are likely to increase. Conservation tillage practices are prevalent in Virginia (41), with many counties predominantly using no-till and minimal tillage to manage corn residue.

The reduction of $G$. zeae-infested residue within wheat and barley fields prior to planting may reduce the impact of future FHB epidemics. However, with the move away from conventional tillage practices (13), research is needed to better understand the influence of the remaining corn residue. Spread from sources of G. zeae inoculum has been reported using a released clone with a unique phenotype $(16,38)$ and released clones with unique genotypes based on differences in alleles (23). Fernando et al. (16) observed a 
$50 \%$ decline of FHB at distances of 1 to $10 \mathrm{~m}$ from inoculum sources and Stack (38) observed a 50\% decline of FHB within 2 to $3 \mathrm{~m}$ of small inoculum sources. Research to date has reported the influence of local inoculum sources on FHB infection within several meters of the source; however, the potential impact of different amounts of corn residue to spread of G. zeae from local inoculum sources has not been examined in detail. We hypothesized that the spread of a released clone of $G$. zeae is greater with increasing amounts of local corn stalk residue. To test this hypothesis, corn stalk pieces $(45,200$, or $410 \mathrm{~g})$ colonized with a single clone of $G$. zeae were released in small, 0.84-m-diameter replicated plots in winter wheat and barley fields in Virginia over 3 years (2008 to 2010). Amplified fragment length polymorphism (AFLP; 42) was used to identify the released clone in heterogeneous background populations of the fungus at the source plots $(0 \mathrm{~m})$ and at $3 \mathrm{~m}$ from the source plots. This genotyping technique has successfully monitored other plant pathogens within heterogeneous populations $(1,4,5,36)$. Assessments were conducted in 31 commercial wheat and barley fields to estimate corn stalk residue coverage in Virginia. An abstract on a portion of this work has been published (22).

\section{Materials and Methods}

Experimental fields. Experiments were conducted in two barley and two soft red winter wheat fields. Barley experiments were conducted in a commercial field in New Kent County, VA (2008), hereafter referred to as BR08, and in an experimental field in Blacksburg, VA (2009), hereafter referred to as BR09. In both years, 'Nomini' barley (moderately resistant to FHB) was planted following corn harvest in a conventional tillage system. Minimal corn residue was present at the time of planting. Wheat was planted in two experimental fields at the Kentland Research Farm of Virginia Tech in Blacksburg in 2009 and 2010, hereafter referred to as WH09 and WH10, respectively. Each wheat field contained 'Tribute', 'Vigoro 9510', 'Southern States 560' (SS560), and 'Pioneer 26R12' soft red winter wheat in strip plots averaging 110 by 260 $\mathrm{m}$. Tribute and Vigoro 9510 are moderately resistant and SS560 and Pioneer 26R12 are susceptible to FHB. Three-meter fallow strips divided the different cultivars. Both wheat fields followed the harvest of corn and were prepared with conventional tillage methods to minimize corn residue at the time of planting.

Field inoculations. One single-spored $G$. zeae strain (Gz_VA_GPS13N4_3-ADON, hereafter referred to as GZVA3) was used to inoculate plots at all four field locations (BR08, BR09, WH09, and WH10). GZVA3 was recovered from diseased wheat in Riner, VA (23). The strain represented the trichothecene mycotoxin 3 -acetyl deoxynivalenol $(3-A D O N)$ genotype $(18,19)$. Mature corn stalks were collected in the fall of each year and dried in an oven at approximately $65^{\circ} \mathrm{C}$ for storage until inoculation. Corn stalks were cut into pieces measuring approximately 10 to $15 \mathrm{~cm}$ and were separated into groups of 5,25 , and 50 pieces with dry weights (prior to autoclaving) of 45, 200, and $410 \mathrm{~g}$, respectively. Corn stalk pieces were stored at room temperature until ready for autoclaving and inoculation. Autoclaved corn stalk pieces were inoculated with GZVA3 and stored in 4-liter plastic containers at ambient room temperature for approximately 10 weeks. Inoculations of BR08 and BR09 were performed on 22 March (New Kent County, VA) and on 3 April (Blacksburg, VA), respectively. Inoculations of WH09 and WH10 were performed on 18 April (Blacksburg, VA) and on 12 April (Blacksburg, VA), respectively. Corn stalk pieces covered with G. zeae mycelia were uniformly distributed in replicated 0.84-m-diameter circular plots (Fig. 1). Perithecia were not observed on corn stalk pieces at the time of inoculation but were present in the weeks before spike collection.

BR08 and BR09 each contained a total of seven plots, six of which had corn stalk pieces inoculated with GZVA3: two plots contained $45 \mathrm{~g}$, two plots contained $200 \mathrm{~g}$, and two plots contained $410 \mathrm{~g}$. One control plot contained $200 \mathrm{~g}$ of noninoculated corn stalk pieces. All plots were separated from each other by $\geq 18 \mathrm{~m}$. In WH09 and WH10, each of the four cultivar strip plots contained a total of five plots, four of which had corn stalk pieces inoculated with GZVA3: two plots contained $45 \mathrm{~g}$ and two plots contained $410 \mathrm{~g}$. One control plot contained $200 \mathrm{~g}$ of noninoculated corn stalk pieces. No chemical or mechanical disturbance of the fields occurred during the study. No additional inoculum was applied, nor was misting used to enhance infection.

Isolation of G. zeae. BR08 spikes were collected 6 May and BR09 spikes were collected 19 May. WH09 spikes were collected 29 May and WH10 spikes were collected 4 June. Collection occurred between Zadoks growth stages 77 and 83 for all fields. Barley and wheat spikes were collected at random directly above each plot $(0 \mathrm{~m})$, at $3 \mathrm{~m}$, and at distances $\geq 18 \mathrm{~m}$ (control plots). A string was secured to a stake in the center of each plot and was used to collect spikes at radii of $3 \mathrm{~m}$ circling the plots. Fifty-five spikes for each replicated barley plot and 40 spikes for each replicated wheat plot were collected at random at distances of 0 and $3 \mathrm{~m}$ from the
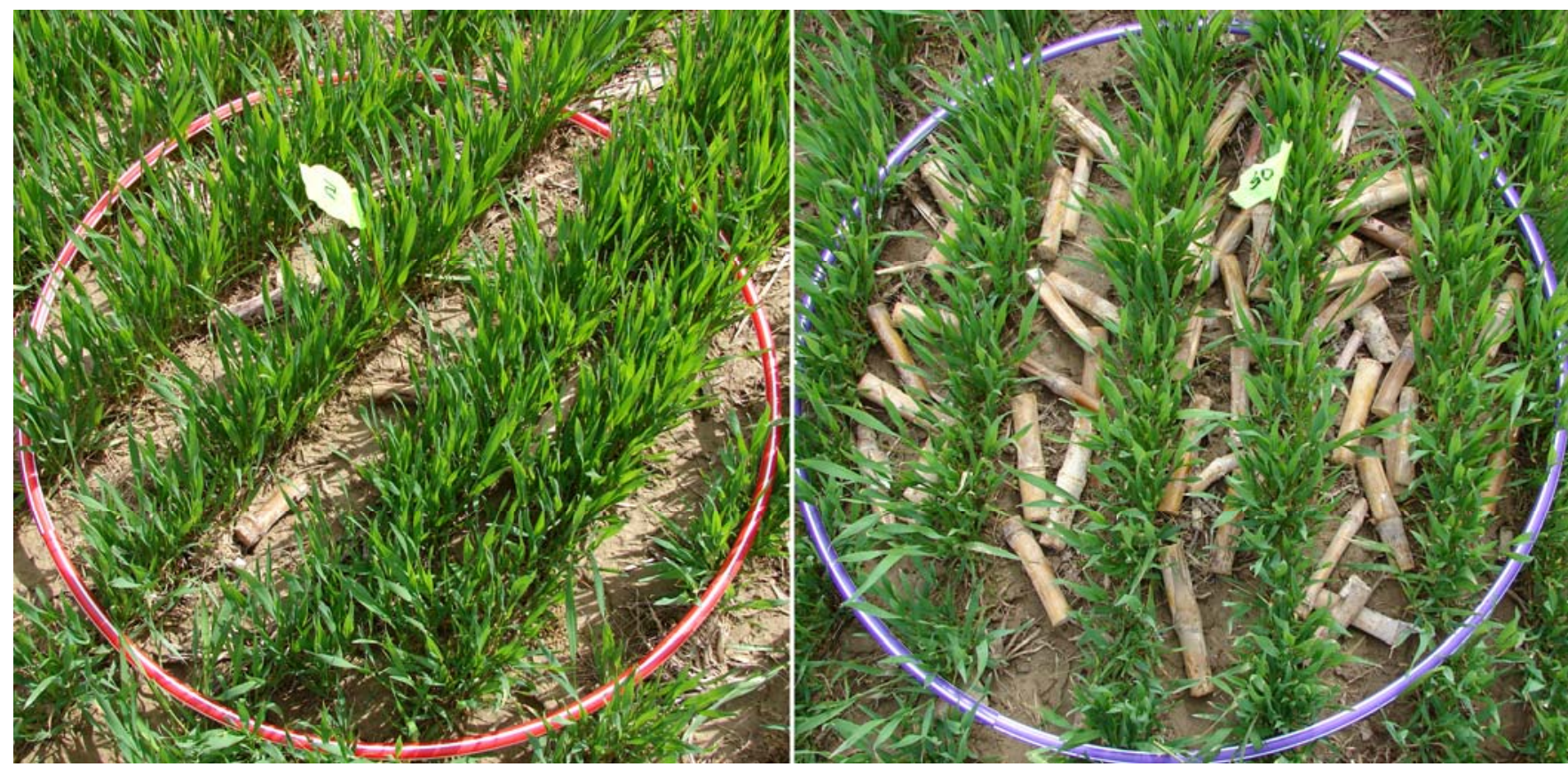

Fig. 1. Experimental 0.84-m-diameter wheat plots containing $45 \mathrm{~g}$ ( 5 stalks, left) and $410 \mathrm{~g}$ (50 stalks, right) of corn stalk pieces colonized with a single clone of Gibberella zeae. 
center of the sources. Collected spikes were assessed for FHB symptoms (i.e., premature bleaching; 3,27 ) from plots containing hundreds of additional spikes. The spikes were then surface disinfested in a $20 \%$ bleach solution for $1 \mathrm{~min}$ and rinsed with distilled water for $1 \mathrm{~min}$. After disinfestation, symptomatic and asymptomatic spikes were plated onto Fusarium-selective medium (FSM) (8) containing neomycin at $0.35 \mathrm{~g} /$ liter (36). Spikes were incubated for 5 to 7 days at ambient room temperature. One colony of Fusarium spp. was subcultured from each collected spike and was plated onto quarter-strength potato dextrose agar (PDA). Single spores of these colonies were plated onto additional plates of quarter-strength PDA after identification of the characteristic red or pink mycelia and macroconidia characteristic of $F$. graminearum (24).

DNA extraction and AFLP analysis. DNA extractions and AFLPs were performed following standard protocols (23). Nine alleles used by Keller et al. (23) were selected to represent the genotype of the released strain GZVA3. Alleles with a frequency lower than $10 \%$ and higher than $90 \%$ within initial populations were excluded from the alleles chosen. Presence or absence of these alleles was scored based on a binary format (i.e., allele present $=1$ and absent $=0$ ) for all recovered isolates. When the profiles of the nine alleles were identical, isolates were considered to be the released clone of G. zeae. If the profiles of the isolates contained eight or fewer alleles that were identical to the released clone, they were considered to be from background sources.

Weather data. Rainfall, humidity, and temperature for BR09, WH09, and WH10 was recorded at 30-min intervals by a Vantage Pro2 weather station (model number 06152; Davis Instruments, Corp., Hayward, CA) located at the Kentland Research Farm of Virginia Tech, Blacksburg. Data were analyzed using WeatherLink Software (version 5.8.1; Davis Instruments, Corp.). No weather data were recorded for BR08.

Statistical analysis. All statistical analyses were performed using the Statistical Analysis System (version 9.2; SAS Institute, Cary, NC). The incidence of G. zeae infection of collected spikes and the recovery of the clone were analyzed using differences of least squares means (Proc. GENMOD). Both incidence and recovery analyses were performed, accounting for the amount of corn residue $(45,200$, and $410 \mathrm{~g})$ and distance from source plots ( 0 and $3 \mathrm{~m})$. BR08, BR09, WH09, and WH10 were analyzed independently of each other. Significance was evaluated at $P<0.05$.

\section{Results}

Incidence of spikes infected by G. zeae (Tables 1 and 2) varied among the test years; therefore, each of the four field experiments was treated separately when calculating statistical significance in decline (i.e., slope) of clone recovery from plots containing different amounts of corn residue (Table 3; Fig. 2).

Weather conditions. From the time of flowering to spike collection for BR09, the temperature range, total rainfall, and average relative humidity were 1.3 to $26.4^{\circ} \mathrm{C}, 116 \mathrm{~mm}$, and $89 \%$, respectively. From the time of flowering to WH09 spike collection, the temperature range, total rainfall, and average relative humidity were 1.3 to $26.8^{\circ} \mathrm{C}, 101 \mathrm{~mm}$, and $79 \%$, respectively. From the time of flowering to WH10 spike collection, the temperature range, total rainfall, and average relative humidity were -1.3 to $30.3^{\circ} \mathrm{C}, 58$ $\mathrm{mm}$, and $83 \%$, respectively.

Barley trials, 2008. BR08 spikes infected by G. zeae (i.e., incidence) were significantly different between plots containing 45 and $200 \mathrm{~g}(P=0.02), 200$ and $410 \mathrm{~g}(P=0.001)$, and 45 and $410 \mathrm{~g}(P$ $<0.0001$ ) (Table 3) of G. zeae-infested corn residue. Incidence of spikes infected by $G$. zeae ranged from 20 to $56 \%$ in inoculated plots and $11 \%$ in the control plot (Table 1). Spikes infected by $G$. zeae were significantly different between 0 and $3 \mathrm{~m}$ for plots containing $200(P=0.001)$ and $410 \mathrm{~g}(P<0.0001)$ but not for plots containing $45 \mathrm{~g}(P=0.73)$ (data not shown). Spikes with incidence attributable to the clone were significantly different between plots containing 45 and $410 \mathrm{~g}(P=0.002$; Table 3$)$ but not between plots containing 45 and $200 \mathrm{~g}(P=0.08)$ or 200 and $410 \mathrm{~g}(P=0.13)$. The steepest decline in clone recovery from 0 to $3 \mathrm{~m}$ (Fig. 2) was observed in plots containing $200 \mathrm{~g}(95 \% ; P=0.001)$ and a more

Table 1. Recovery of the released clone of Gibberella zeae from barley spikes collected at 0 (above the source), 3 , and $\geq 18 \mathrm{~m}$ from the center of the released inoculum sources ${ }^{\mathrm{a}}$

\begin{tabular}{|c|c|c|c|c|c|c|c|}
\hline \multirow[b]{2}{*}{ Field, year ${ }^{b}$} & \multirow[b]{2}{*}{ Inoc. $\operatorname{conc} c^{c}$} & \multirow[b]{2}{*}{ Plots $^{d}$} & \multirow[b]{2}{*}{ Distance $(m)$ from center ${ }^{e}$} & \multicolumn{3}{|c|}{ Spikes infected by } & \multirow[b]{2}{*}{ Decline $(\%)^{\mathrm{i}}$} \\
\hline & & & & G. zeae $(\%)^{\mathrm{f}}$ & Background isolates $(\%)^{\mathrm{g}}$ & Clone $(\%)^{\text {h }}$ & \\
\hline BR08 & 45 & 2 & 0 & 20 & 7 & 13 & $\ldots$ \\
\hline BR08 & 45 & 2 & 3 & 18 & 16 & 2 & 85 \\
\hline BR08 & 200 & 2 & 0 & 35 & 13 & 22 & $\ldots$ \\
\hline BR08 & 200 & 2 & 3 & 15 & 14 & 1 & 95 \\
\hline BR08 & 410 & 2 & 0 & 56 & 25 & 31 & $\ldots$ \\
\hline BR08 & 410 & 2 & 3 & 24 & 19 & 5 & 84 \\
\hline BR08 & Control & 1 & $\geq 18$ & 11 & 9 & 2 & $\ldots$ \\
\hline BR09 & 45 & 2 & 0 & 6 & 1 & 5 & $\ldots$ \\
\hline BR09 & 45 & 2 & 3 & 3 & 3 & 0 & 100 \\
\hline BR09 & 200 & 2 & 0 & 6 & 4 & 3 & $\ldots$ \\
\hline BR09 & 200 & 2 & 3 & 5 & 3 & 3 & 0 \\
\hline BR09 & 410 & 2 & 0 & 5 & 0 & 14 & $\ldots$ \\
\hline BR09 & 410 & 2 & 3 & 5 & 3 & 3 & 79 \\
\hline BR09 & Control & 1 & $\geq 18$ & 9 & 7 & 2 & $\ldots$ \\
\hline
\end{tabular}

${ }^{a}$ Percentages were calculated from 110 barley spikes collected at $0 \mathrm{~m}$ (above the source), 110 spikes at $3 \mathrm{~m}$, and 55 spikes at $\geq 18 \mathrm{~m}$ from the center of the released sources.

b 'Nomini' barley was planted in fields in New Kent County, VA in 2008 and in Blacksburg, VA in 2009.

${ }^{c}$ Inoculation concentration. Plots were inoculated with G. zeae-infested corn stalk pieces with concentrations of 45,200 , and $410 \mathrm{~g}$ (dry weight after autoclaving). Control plots contained $200 \mathrm{~g}$ of noninoculated corn stalk pieces.

${ }^{\mathrm{d}}$ Number of 0.84 -m-diameter plots containing clonal inocula (source, $0 \mathrm{~m}$ ) or no inocula (control, $\geq 18 \mathrm{~m}$ ) separated by $\geq 18 \mathrm{~m}$ within commercial fields or number of circular sampling areas at $3 \mathrm{~m}$ from centers of source plots.

e Distance $(\mathrm{m})$ from center of released source. Spikes were collected at $0 \mathrm{~m}$ (above the source), and $3 \mathrm{~m}$ from released sources. Spikes were also sampled from control plots at distances $\geq 18 \mathrm{~m}$.

${ }^{\mathrm{f}}$ Number of infected spikes divided by the total number of spikes collected at 0,3 , and $\geq 18 \mathrm{~m}$ from the center of the released sources. Isolates of $G$. zeae were recovered from 110 barley spikes per sampling-distance. Percentages rounded to integer values.

g Background isolates of G. zeae recovered from total number of spikes collected. Percentages rounded to integer values.

${ }^{\mathrm{h}}$ Released clone of $G$. zeae recovered from total number of spikes collected. Clones were distinguished from background populations using amplified fragment length polymorphism analysis. Percentages rounded to integer values.

${ }^{i}$ Decline of recovery of the released clone of G. zeae from $0 \mathrm{~m}$ (above the source) to $3 \mathrm{~m}$ from the source plots. Decline from source plots to the control plots was not calculated due to the unknown origin of the plot most influencing the recovered G. zeae clone. Percentages rounded to integer values. 
gradual but significant decline from plots containing 45 (85\%; $P=$ 0.01 ; Table 3$)$ and $410 \mathrm{~g}(84 \% ; P<0.0001$; Table 3$) . P$ values for 200-g plots are not shown in Table 3 for BR08 or BR09.

Barley trials, 2009. Fewer infected spikes and fewer infections attributable to the clone were observed for BR09 (Table 1). Low incidences of spikes infected by G. zeae ranged from 5 to $6 \%$ in inoculated plots and $9 \%$ in the control plot (Table 1). Incidence of BR09 spikes infected by $G$. zeae were not significantly different between plots containing 45 and $200 \mathrm{~g}(P=1.00), 200$ and $410 \mathrm{~g}$ $(P=0.78)$, or 45 and $410 \mathrm{~g}(P=0.78)$. No significant difference was observed for spikes infected with $G$. zeae between 0 and $3 \mathrm{~m}$ for plots containing 45, 200, or $410 \mathrm{~g}$ (data not shown). Spikes with incidence attributable to the clone were significantly different between plots containing 200 and $410 \mathrm{~g}(P=0.01)$ but not for plots containing 45 and $200 \mathrm{~g}(P=0.32)$ and 45 and $410 \mathrm{~g}(P=0.05$; Table 3$)$. The steepest decline in recovery of the clone from 0 to 3 $\mathrm{m}$ (Fig. 2) was observed in plots containing $45 \mathrm{~g}(100 \% ; P<$ 0.0001 ; Table 3 ) and a more gradual decline in plots containing $410 \mathrm{~g}(79 \% ; P=0.01$; Table 3$)$. There was no decline in clone recovery between 0 and $3 \mathrm{~m}$ for plots containing $200 \mathrm{~g}$.

Wheat trials, 2009. Incidence of spikes infected by G. zeae ranged from 28 to $100 \%$ in susceptible inoculated plots, 70 to $94 \%$

Table 2. Recovery of the released clone of Gibberella zeae from soft red winter wheat spikes collected at 0 (above the source), 3 , and $\geq 18 \mathrm{~m}$ from the center of the released inoculum sources ${ }^{\mathrm{a}}$

\begin{tabular}{|c|c|c|c|c|c|c|c|c|}
\hline \multirow[b]{2}{*}{ Field, year ${ }^{b}$} & \multirow[b]{2}{*}{ Cultivar ${ }^{\mathrm{c}}$} & \multirow[b]{2}{*}{ Inoc. conc. ${ }^{d}$} & \multirow[b]{2}{*}{ Plots $^{e}$} & \multirow[b]{2}{*}{ Distance $(\mathbf{m})^{\mathbf{f}}$} & \multicolumn{3}{|c|}{ Spikes infected by } & \multirow[b]{2}{*}{ Decline $(\%)^{\mathrm{j}}$} \\
\hline & & & & & G. zeae $(\%)^{\mathrm{g}}$ & Background $^{\text {h }}$ & Clone $(\%)^{\mathrm{i}}$ & \\
\hline WH09 & Tribute & 45 & 2 & 0 & 70 & 51 & 19 & \\
\hline WH09 & Tribute & 45 & 2 & 3 & 25 & 23 & 3 & 84 \\
\hline WH09 & Tribute & 410 & 2 & 0 & 94 & 75 & 19 & $\ldots$ \\
\hline WH09 & Tribute & 410 & 2 & 3 & 23 & 0 & 23 & $0^{\mathrm{k}}$ \\
\hline WH09 & Tribute & Control & 1 & $\geq 18$ & 8 & 0 & 8 & $\ldots$ \\
\hline WH09 & Vigoro 9510 & 45 & 2 & 0 & 79 & 58 & 21 & $\ldots$ \\
\hline WH09 & Vigoro 9510 & 45 & 2 & 3 & 46 & 43 & 4 & 81 \\
\hline WH09 & Vigoro 9510 & 410 & 2 & 0 & 94 & 76 & 18 & \\
\hline WH09 & Vigoro 9510 & 410 & 2 & 3 & 75 & 65 & 10 & 44 \\
\hline WH09 & Vigoro 9510 & Control & 1 & $\geq 18$ & 23 & 20 & 3 & $\ldots$ \\
\hline WH09 & SS560 & 45 & 2 & 0 & 28 & 15 & 13 & $\ldots$ \\
\hline WH09 & SS560 & 45 & 2 & 3 & 8 & 3 & 5 & 62 \\
\hline WH09 & SS560 & 410 & 2 & 0 & 88 & 66 & 21 & $\ldots$ \\
\hline WH09 & SS560 & 410 & 2 & 3 & 30 & 18 & 13 & 38 \\
\hline WH09 & SS560 & Control & 1 & $\geq 18$ & 8 & 8 & 0 & $\ldots$ \\
\hline WH09 & Pioneer 26R12 & 45 & 2 & 0 & 71 & 55 & 16 & $\ldots$ \\
\hline WH09 & Pioneer 26R12 & 45 & 2 & 3 & 33 & 30 & 3 & 81 \\
\hline WH09 & Pioneer 26R12 & 410 & 2 & 0 & 100 & 78 & 23 & $\ldots$ \\
\hline WH09 & Pioneer 26R12 & 410 & 2 & 3 & 75 & 59 & 16 & 30 \\
\hline WH09 & Pioneer 26R12 & Control & 1 & $\geq 18$ & 23 & 23 & 0 & $\ldots$ \\
\hline WH10 & Tribute & 45 & 2 & 0 & 5 & 0 & 13 & $\ldots$ \\
\hline WH10 & Tribute & 45 & 2 & 3 & 0 & 0 & 0 & 100 \\
\hline WH10 & Tribute & 410 & 2 & 0 & 25 & 0 & 25 & $\ldots$ \\
\hline WH10 & Tribute & 410 & 2 & 3 & 8 & 1 & 6 & 76 \\
\hline WH10 & Tribute & Control & 1 & $\geq 18$ & 0 & 0 & 3 & $\ldots$ \\
\hline WH10 & Vigoro 9510 & 45 & 2 & 0 & 4 & 4 & 0 & $\ldots$ \\
\hline WH10 & Vigoro 9510 & 45 & 2 & 3 & 3 & 3 & 0 & 0 \\
\hline WH10 & Vigoro 9510 & 410 & 2 & 0 & 40 & 20 & 20 & $\ldots$ \\
\hline WH10 & Vigoro 9510 & 410 & 2 & 3 & 5 & 1 & 4 & 80 \\
\hline WH10 & Vigoro 9510 & Control & 1 & $\geq 18$ & 0 & 0 & 0 & $\ldots$ \\
\hline WH10 & SS560 & 45 & 2 & 0 & 3 & 0 & 4 & $\ldots$ \\
\hline WH10 & SS560 & 45 & 2 & 3 & 0 & 0 & 0 & 100 \\
\hline WH10 & SS560 & 410 & 2 & 0 & 8 & 0 & 35 & $\ldots$ \\
\hline WH10 & SS560 & 410 & 2 & 3 & 0 & 0 & 6 & 83 \\
\hline WH10 & SS560 & Control & 1 & $\geq 18$ & 3 & 3 & 0 & $\ldots$ \\
\hline WH10 & Pioneer 26R12 & 45 & 2 & 0 & 3 & 0 & 14 & $\ldots$ \\
\hline WH10 & Pioneer 26R12 & 45 & 2 & 3 & 10 & 9 & 1 & 93 \\
\hline WH10 & Pioneer 26R12 & 410 & 2 & 0 & 46 & 1 & 45 & $\ldots$ \\
\hline WH10 & Pioneer 26R12 & 410 & 2 & 3 & 16 & 9 & 8 & 82 \\
\hline WH10 & Pioneer 26R12 & Control & 1 & $\geq 18$ & 3 & 3 & 0 & $\ldots$ \\
\hline
\end{tabular}

${ }^{a}$ Percentages were calculated from 80 wheat spikes collected at $0 \mathrm{~m}$ (above the source), 80 spikes at $3 \mathrm{~m}$, and 40 spikes at $\geq 18 \mathrm{~m}$ from the center of the released sources.

b Wheat was planted in commercial fields in 2009 and 2010 in Blacksburg, VA.

' Moderately resistant 'Tribute' and 'Vigoro 9510' and the susceptible 'SS560' and 'Pioneer 26R12' were planted.

${ }^{\mathrm{d}}$ Inoculation concentration. Plots were inoculated with Gibberella zeae-infested corn stalk pieces with concentrations of 45 and $410 \mathrm{~g}$ (dry weight after autoclaving). Control plots contained $200 \mathrm{~g}$ of noninoculated corn stalk pieces.

${ }^{\mathrm{e}}$ Number of 0.84 -m-diameter plots containing clonal inocula (source, $0 \mathrm{~m}$ ) or no inocula (control, $\geq 18 \mathrm{~m}$ ) separated by $\geq 18 \mathrm{~m}$ within commercial fields or number of circular sampling areas at $3 \mathrm{~m}$ from centers of source plots.

${ }^{\mathrm{f}}$ Distance $(\mathrm{m})$ from center of released source. Spikes were collected at $0 \mathrm{~m}$ (above the source) and $3 \mathrm{~m}$ from the center of the released sources. Spikes were also sampled from control plots at distances $\leq 18 \mathrm{~m}$.

g Number of infected spikes divided by the total number of spikes collected at 0 and $3 \mathrm{~m}$ from the center of the released sources. Isolates of G. zeae were recovered from 80 wheat spikes in 2009 and 2010. Percentages rounded to integer values.

${ }^{\mathrm{h}}$ Released clone of G. zeae recovered from total number of wheat spikes collected. Clones were distinguished from background populations using AFLP analysis. Percentages rounded to integer values.

i Background isolates of G. zeae recovered from total number of wheat spikes collected. Percentages rounded to integer values.

${ }^{\mathrm{j}}$ Decline of recovery of the released clone of $G$. zeae from 0 (above the source) to $3 \mathrm{~m}$ from the source plots. Decline from source plots to the control plots was not calculated due to the unknown origin of the plot most influencing the recovered G. zeae clone. Percentages rounded to integer values.

${ }^{\mathrm{k}}$ No decline was seen at this field plot location. An increase of $17 \%$ occurred from the source to $3 \mathrm{~m}$. This was the only instance where this trend was observed. 
in moderately resistant inoculated plots, and 8 to $23 \%$ in control plots (Table 2). The incidences of WH09 spikes infected by G. zeae were significant between plots containing 45 and $410 \mathrm{~g}$ in both susceptible and moderately resistant cultivars (Table 3 ) and between 0 and $3 \mathrm{~m}$ for plots containing 45 and $410 \mathrm{~g}$ in all cultivars (data not shown). However, no significant differences were observed in spike incidence attributable to the clone for the four cultivars between plots containing 45 and $410 \mathrm{~g}$ (Table 3), although greater differences were observed between the susceptible cultivars than the moderately resistant cultivars (Table 2). The decline in spike infection attributable to the clone from 0 to $3 \mathrm{~m}$ (Table 2) for Tribute, Vigoro 9510, SS560, and Pioneer $26 \mathrm{R} 12$ was $84,81,62$, and $81 \%$ for plots containing $45 \mathrm{~g}$ and 0 (an increase of $17 \%$ was observed), 44, 38, and $30 \%$ for plots containing $410 \mathrm{~g}$, respectively. The decline in spike infection attributable to the clone from 0 to $3 \mathrm{~m}$ in plots containing $45 \mathrm{~g}$ was significant for all cultivars, with the exception of SS560 ( $P=0.10$; Table 3$)$, and no significance was observed for any plots containing $410 \mathrm{~g}$ (Table 3 ).

Wheat trials, 2010. Incidence of spike infection by G. zeae ranged from 3 to $46 \%$ in susceptible inoculated plots, 4 to $40 \%$ in moderately resistant inoculated plots, and 0 to $3 \%$ in control plots (Table 2). Significant differences in spike infection by G. zeae were observed for Tribute, Vigoro 9510, and Pioneer 26R12 between plots containing 45 and $410 \mathrm{~g}$ (Table 3). Significance differences in spike infection were observed between 0 and $3 \mathrm{~m}$ for plots containing $45 \mathrm{~g}$ in Tribute $(P<0.0001)$ and for plots containing $410 \mathrm{~g}$ for Tribute $(P=0.004)$, Vigoro $9510(P<0.0001)$, and Pioneer 26R12 $(P<0.0001)$ (data not shown). A higher percentage of spike infection attributable to the clone was observed for plots containing $410 \mathrm{~g}$ for all cultivars when compared with plots containing $45 \mathrm{~g}$ (Table 2). Significant differences in spike infection attributable to the clone in plots containing 45 and $410 \mathrm{~g}$ were observed for the susceptible cultivars but not for the moderately resistant cultivars, although a $P$ value of 0.05 was reported for Tribute, which may be considered significant (Table 3). The moderately resistant cultivars had less recovery of the clone in $410-\mathrm{g}$ plots compared with the 410-g plots of the susceptible cultivars (Table 2). The decline in spike infection attributable to the clone from 0 to $3 \mathrm{~m}$ (Fig. 2) for Tribute, Vigoro 9510, SS560, and Pioneer 26R12 was 100, 0 (no clones recovered), 100, and 93\% for plots containing $45 \mathrm{~g}$ and $76,80,83$, and $82 \%$ for plots containing $410 \mathrm{~g}$, respectively. The decline in spike infection attributable to the clone from 0 to $3 \mathrm{~m}$ in plots containing 45 and $410 \mathrm{~g}$ was significant for all cultivars, with the exception of the plots containing $45 \mathrm{~g}$ for Vigoro $9510(P=1.00$; Table 3$)$.

\section{Discussion}

Data from our field experiments generally supported our hypothesis that the intensity of spread of a released clone of G. zeae is greater with increasing amounts of local corn stalk residue. For WH09 and WH10, steeper declines (i.e., steeper slopes) were observed in nearly all of the plots (with the exception of Vigoro 9510 in WH10) containing $45 \mathrm{~g}$ compared with those with $410 \mathrm{~g}$ suggesting greater spread from larger amounts of corn residue. This trend was also true in BR09; the decline in spike infection attributable to the released clone was $79 \%$ for $410 \mathrm{~g}$ and $100 \%$ for $45 \mathrm{~g}$. During a high epidemic year for FHB, larger amounts of corn residue may influence spread from a source of inoculum more than smaller amounts of corn residue. However, it may be difficult to predict the impact of local corn stalk residue during years highly favorable for FHB infection (29).

The decline in the recovery of the clone within a distance of $3 \mathrm{~m}$ was similar to that reported by Keller et al. (23). Plots containing larger amounts of residue $(410 \mathrm{~g})$ resulted in an average overall decline of 84 and $79 \%$ for BR08 and BR09, respectively, and 28 and $80 \%$ for WH09 and WH10, respectively. The clone was also recovered at distances $\geq 18 \mathrm{~m}$ from inoculum sources. However, due to the lower percentages of recovery, the spread of the clone from source plots may be diminishing within meters from the sources. The overall recovery of the clone was lower in 2009 , and higher percentages of infection by background isolates were observed. In 2010, the overall recovery of the clone was higher. However, infection by background isolates in 2010 was lower than in 2009 , perhaps a consequence of unfavorable conditions for the production of background inocula.

Larger amounts of infested residue were used to "mimic" higher percentages of corn stalk residue coverage in commercial wheat fields. A residue survey conducted in 31 commercial wheat and barley fields in 10 counties in Virginia using a line transect method $(21,30)$ showed that $42 \%(13 / 31)$ of the fields had residue coverage comparable with the residue coverage of experimental plots containing $410 \mathrm{~g}$ (75\% coverage) of inoculated corn stalks (unpublished observations). Thus, nearly half of the fields in Virginia would be expected to have a high inoculum potential, should environmental conditions be favorable for regional FHB epidemics. In such cases, the use of minimal or conventional tillage may help reduce within-field inoculum potential for FHB.

FHB incidence varied across the wheat and barley field experiments. It has been shown that FHB epidemics may be linked to environmental conditions that are favorable for infection and resulting disease progression (17). Similar temperature ranges were

Table 3. Probabilities from a statistical analysis comparing 45 and $410 \mathrm{~g}$ of inoculated corn stalk pieces in wheat and barley research plots from 2008 to $2010^{\mathrm{a}}$

\begin{tabular}{|c|c|c|c|c|c|}
\hline \multirow[b]{2}{*}{ Cultivarb } & \multirow[b]{2}{*}{ Field, year } & \multirow{2}{*}{$\frac{\text { Spikes infected by }}{\text { G. zeae }}$} & \multicolumn{3}{|c|}{ Spikes infected by clone at } \\
\hline & & & $0 \mathrm{~m}: 45$ vs. $410 \mathrm{~g}^{\mathrm{d}}$ & 45 g: 0 vs. $3 \mathrm{~m}^{\mathrm{e}}$ & 410 g: 0 vs. $3 \mathrm{~m}^{\mathrm{f}}$ \\
\hline Nomini & BR08 & $<0.0001$ & 0.002 & 0.01 & $<0.0001$ \\
\hline Nomini & BR09 & 0.78 & 0.05 & $<0.0001$ & 0.01 \\
\hline Tribute & WH09 & 0.0004 & 1.000 & 0.004 & 0.56 \\
\hline Vigoro 9510 & WH09 & 0.01 & 0.55 & 0.003 & 0.17 \\
\hline SS560 & WH09 & $<0.0001$ & 0.14 & 0.10 & 0.14 \\
\hline Pioneer 26R12 & WH09 & $<0.0001$ & 0.32 & 0.01 & 0.32 \\
\hline Tribute & WH10 & 0.001 & 0.05 & $<0.0001$ & 0.002 \\
\hline Vigoro 9510 & WH10 & $<0.0001$ & 1.000 & 1.000 & 0.004 \\
\hline SS560 & WH10 & 0.17 & $<0.0001$ & $<0.0001$ & $<0.0001$ \\
\hline Pioneer 26R 12 & WH10 & $<0.0001$ & $<0.0001$ & 0.02 & $<0.0001$ \\
\hline
\end{tabular}

a The GENMOD procedure was used to determine significance of differences of least squares means for each variable shown. All comparisons were performed accounting for amount of corn residue $(45,200$, and $410 \mathrm{~g})$ and distance from source plots $(0$ and $3 \mathrm{~m})$.

b Moderately resistant 'Nomini' barley was planted in 2008 and 2009 and moderately resistant 'Tribute' and 'Vigoro 9510' wheat and the susceptible 'SS560' and 'Pioneer 26R12' wheat were planted in 2009 and 2010.

${ }^{c}$ Number of infected spikes divided by the total number of spikes collected at $0 \mathrm{~m}$ in plots containing 45 and $410 \mathrm{~g}$ of Gibberella zeae-infested corn residue.

${ }^{\mathrm{d}}$ Incidence of spike infection attributable to the released clone within 45- and 410-g plots.

${ }^{\mathrm{e}}$ Incidence of spike infection attributable to the released clone within 45-g plots when accounting for distances of 0 and $3 \mathrm{~m}$.

${ }^{\mathrm{f}}$ Incidence of spike infection attributable to the released clone within 410-g plots when accounting for distances of 0 and $3 \mathrm{~m}$. 
recorded for BR09, WH09, and WH10. Although a larger amount of total rainfall was recorded for BR09 $(116 \mathrm{~mm})$, the rainfall events occurred sporadically between the time of flowering and spike collection. For WH09, rainfall was sporadic throughout flowering but became more frequent in the days just prior to spike collection. This may have contributed to higher percentages of FHB incidence for WH09. The timing and duration of rainfall is linked to G. zeae inoculum production $(17,32)$, and regional, background sources of inoculum may contribute to FHB epidemics regardless of local management practices (25). It is possible that FHB incidence may have been underestimated due to asymptomatic spikes that resulted in colonies of G. zeae on FSM plates. Multiple infections on the same spike caused by either the clone or background inoculum may have been underestimated when only one colony of G. zeae was isolated from the collected spikes. Percentage of spikes infected by the clone were observed in some instances to be higher than the percentage of spikes infected by $G$. zeae in barley plots (BR09) and wheat plots (WH10). This may be the result of asymptomatic spikes infected at or before flowering, or even late infection $(10,11)$.

Significant differences in spike infection attributable to the released clone in plots containing 45 and $410 \mathrm{~g}$ were observed in WH10 for the susceptible cultivars, but not for the moderately resistant cultivars. The moderately resistant cultivars had less recovery of the clone in 410-g plots compared with the 410-g plots of the susceptible cultivars. For WH09 and WH10, both moderately resistant cultivars and susceptible cultivars were chosen based on similar flowering dates (20) to minimize differences in exposure to the released inoculum. Larger amounts of corn residue generally had less influence on clone recovery in plots containing a moderately resistant wheat cultivar than those containing a susceptible wheat cultivar.

Cultivar selection and tillage strategy for winter wheat must be made prior to fall planting, well in advance of accurate and reliable disease forecasting information for FHB (12). Conservation tillage practices are common in Virginia (41) and will continue to sustain potential inoculum sources of $G$. zeae as long as corn residues remain on the soil surface $(13,27)$. The continued use of conservation tillage practices in the United States will likely contribute to the continued availability of regional, atmospheric populations of G. zeae. Consequently, integrated strategies to manage FHB may need to be employed across wheat and barley production regions $(13,26)$. McMullen et al. (26) reported lower field severity and DON levels when multiple FHB management strategies were implemented. For hard red winter wheat, hard red spring wheat, durum wheat, hard red winter wheat, and soft red winter wheat grown in North Dakota, the planting of a moderately resistant cultivar reduced FHB levels when combined with another management strategy (fungicide or crop rotation) (26). Miller et al. (28) reported tillage practices to be less likely to reduce FHB levels than the planting of a moderately resistant cultivar. Regardless of the management strategy utilized by wheat and barley growers, environmental conditions conducive for FHB may still negatively impact disease levels (17). The use of minimal or conventional tillage may reduce $G$. zeae inoculum. However, in years highly favorable to FHB, even small amounts of corn residue may impact the spread of $G$. zeae inoculum. Ongoing research with different amounts of naturally overwintered corn residue in field experiments $(6,7)$ will
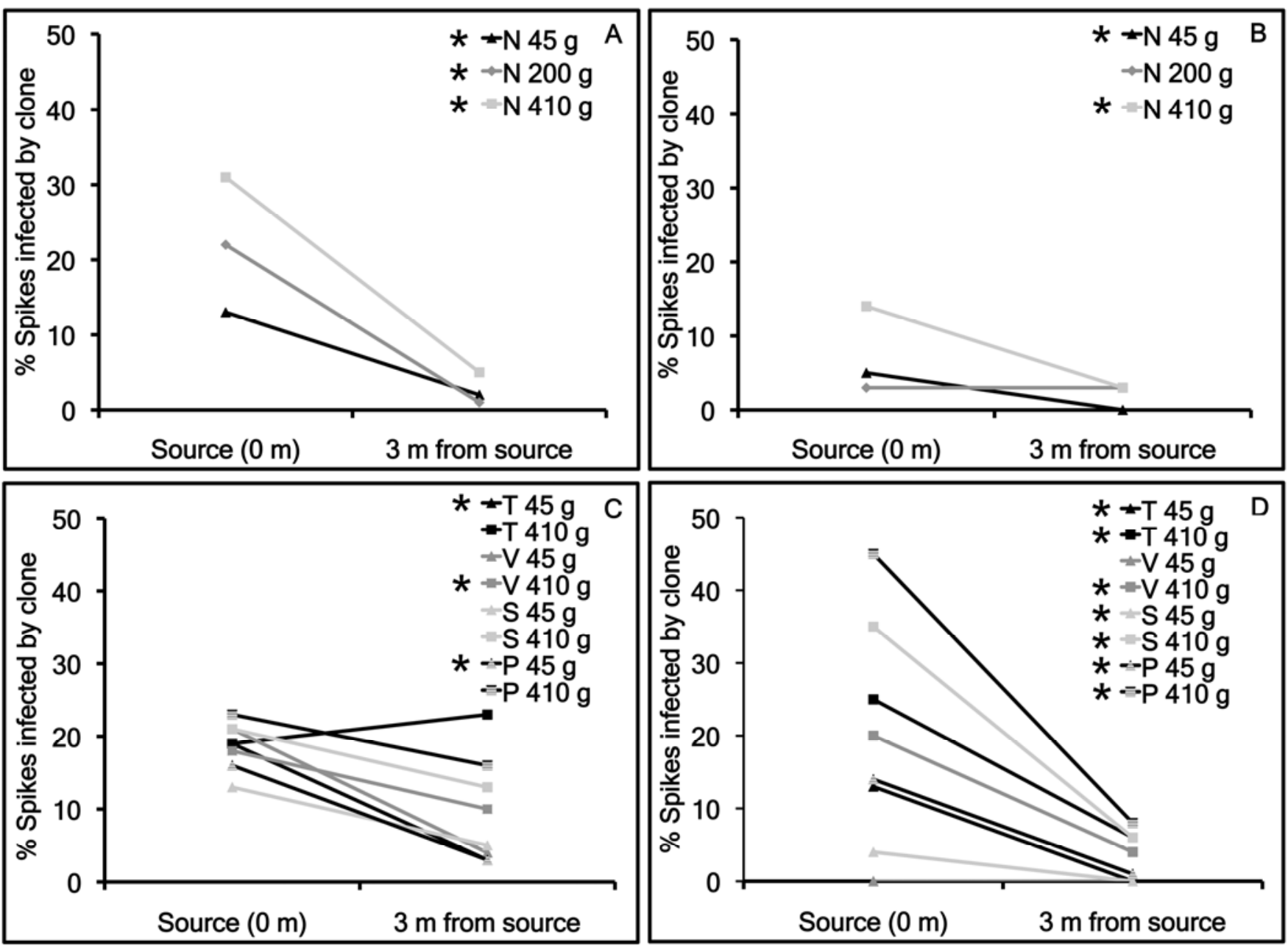

Fig. 2. Effect of the amount of corn residue on the decline from $0 \mathrm{~m}$ (above the source) to $3 \mathrm{~m}$ of the released clone of Gibberella zeae in A, BR08; $B$, BR09; C, WH09; and D, WH10 replicated field plots. Results for the moderately resistant 'Nomini' are shown in A and B. Results from two moderately resistant 'Tribute' (T) and 'Vigoro 9510' (V) wheat and two susceptible 'SS560' (S) and 'Pioneer 26R12' $(P)$ wheat are shown in $C$ and D. An asterisk $\left(^{*}\right)=$ significant difference in decline at $P<0.05$. 
help determine whether similar trends of local spike infection gradients are seen using naturally infested corn residue.

\section{Acknowledgments}

We thank J. Wooge, T. Sowers, C. Keith, F. Davis, J. Stump, J. Cianchetti, and B. Saville for their excellent field support; Virginia Cooperative Extension Agents K. Balderson, P. Davis, W. Lawrence, M. Lewis, D. Moore, M. Saphir, C. Schiemann, and C. Stafford; G. Bergstrom and K. Waxman for their much appreciated advice; K. Winters and G. Nelson for technical assistance; J. Kensler and Z. Fang from the Virginia Tech Department of Statistics and M. Jusino for their statistical assistance; and two anonymous reviewers for their constructive comments on this manuscript.

\section{Literature Cited}

1. Akinsanmi, O. A., Backhouse, D., Simpfendorfer, S., and Chakraborty, S. 2006. Genetic diversity of Australian Fusarium graminearum and $F$. pseudograminearum. Plant Pathol. 55:494-504.

2. Anonymous. 2010. Guidance for Industry and FDA: Advisory Levels for Deoxynivalenol (DON) in Finished Wheat Products for Human Consumption and Grains and Grain By-Products used for Animal Feed. U. S. Department of Health and Human Services, Food and Drug Administration.

3. Bai, G., and Shaner, G. 1994. Scab of wheat: prospects for control. Plant Dis. 78:760-766.

4. Bayon, C., Pei, M. H., Ruiz, C., Hunter, T., Karp, A., and Tubby, I. 2009. Genetic structure and population dynamics of a heteroecious plant pathogen Melampsora larici-epitea in short-rotation coppice willow plantations. Mol. Ecol. 18:3006-3019.

5. Bennett, R. S., Milgroom, M. G., Sainudiin, R., Cunfer, B. M., and Bergstrom, G. C. 2007. Relative contribution of seed-transmitted inoculum to foliar populations of Phaeosphaeria nodorum. Phytopathology 97:584591.

6. Bergstrom, G. C., and Waxman, K. D. 2008. Microplots in commercial wheat fields for quantifying the local contribution of Gibberella zeae from natural corn debris to Fusarium head blight and deoxynivalenol accumulation. Pages 6-8 in: Proc. 2008 Natl. Fusarium Head Blight Forum, Indianapolis, IN.

7. Bergstrom, G. C., Waxman, K. D., Schmale, D. G., III, Bradley, C. A., Sweets, L. E., Wegulo, S. N., and Keller, M. D. 2010. Effects of within-field corn debris in microplots on FHB and DON in eleven U.S. wheat environments in 2010. Pages 69-70 in: Proc. 2010 Natl. Fusarium Head Blight Forum, Milwaukee, WI.

8. Burgess, L. W., Summerell, B. A., Bullock, S., Gott, K. P., and Backhouse, D. 1994. Laboratory Manual for Fusarium Research, 3rd ed. University of Sydney, Australia.

9. Cowger, C., and Arrellano, C. 2010. Plump kernels with high deoxynivalenol linked to late Gibberella zeae infection and marginal disease conditions in winter wheat. Phytopathology 100:719-728.

10. Cowger, C., Patton-Özkurt, J., Brown-Guedira, G., and Perugini, L. 2009. Post-anthesis moisture increased Fusarium head blight and deoxynivalenol levels in North Carolina winter wheat. Phytopathology 99:320-327.

11. Del Ponte, E. M., Fernandes, J. M. C., and Bergstrom, G. C. 2007. Influence of growth stage on Fusarium head blight and deoxynivalenol production in wheat. J. Phytopathol. 155:577-581.

12. De Wolf, E. D., Madden, L. V., and Lipps, P. E. 2003. Risk assessment models for wheat Fusarium head blight epidemics based on within-season weather data. Phytopathology 93:428-435.

13. Dill-Macky, R. 2008. Cultural control practices for Fusarium head blight: problems and solutions. In: Cereal Res. Commun. 3rd Int. FHB Symp. Szeged, Hungary.

14. Dill-Macky, R., and Jones, R. K. 2000. The effect of previous crop residues and tillage on Fusarium head blight of wheat. Plant Dis. 84:71-76.

15. Fernando, W. G. D., Miller, J. D., Seaman, W. L., Seifert, K., and Paulitz, T. C. 2000. Daily and seasonal dynamics of airborne spores of Fusarium graminearum and other Fusarium species sampled over wheat plots. Can. J. Bot. 78:497-505.

16. Fernando, W. G. D., Paulitz, T. C., Seaman, W. L., Dutilleul, P., and Miller, J. D. 1997. Head blight gradients caused by Gibberella zeae from area sources of inoculum in wheat field plots. Phytopathology 87:414-421.

17. Francl, L., Shaner, G., Bergstrom, G., Gilbert, J., Pedersen, W., Dill-Macky, R., Sweets, L., Corwin, B., Jin, Y., Gallenberg, D., and Wiersma, J. 1999. Daily inoculum levels of Gibberella zeae on wheat spikes. Plant Dis. 83:662-666.

18. Gale, L. R., Ward, T. J., Balmas, V., and Kistler, H. C. 2007. Population subdivision of Fusarium graminearum sensu stricto in the upper midwest- ern United States. Phytopathology 97:1434-1439.

19. Goswami, R. S., and Kistler, H. C. 2004. Heading for disaster: Fusarium graminearum on cereal crops. Mol. Plant Pathol. 5:515-525.

20. Haran, M., Bhat, K. S., Molineros, J., and DeWolf, E. 2009. Estimating the risk of a crop epidemic from coincident spacio-temporal processes. J. Agric. Biol. Environ. Stat. 15:158-175.

21. Hickman, J. S., and Schoenberger, D. L. 1989. Corn residue: estimating corn residue. Kans. State Univ. Coop. Ext. Serv. 5-89-45M and 5-92-5M.

22. Keller, M. D., Thomason, W. E., and Schmale, D.G., III. 2010. The recovery of released clones of Gibberella zeae from winter wheat and barley is influenced by the amount of local corn stalk residue. Page 84 in: Proc. 2010 Natl. Fusarium Head Blight Forum, Milwaukee, WI.

23. Keller, M. D., Waxman, K. D., Bergstrom, G. C., and Schmale, D. G., III 2010. Local distance of wheat spike infection by released clones of Gibberella zeae disseminated from infested corn residue. Plant Dis. 94:1151-1155.

24. Leslie, J. F., and Summerell, B. A. 2006. The Fusarium Laboratory Manual. Blackwell Publishing.

25. Maldonado-Ramirez, S. L., Schmale, D. G., Shields, E. J., and Bergstrom, G. C. 2005. The relative abundance of viable spores of Gibberella zeae in the planetary boundary layer suggests the role of long-distance transport in regional epidemics of Fusarium head blight. Agric. For. Meteorol. 132:20 27.

26. McMullen, M., Halley. S., Schatz, B., Meyer, S., Jordahl, J., and Ransom, J. 2008. Integrated strategies for Fusarium head blight management in the United States. In: Cereal Res. Commun. 3rd Int. FHB Symp. Szeged, Hungary.

27. McMullen, M. P., Jones, R., and Gallenberg, D. 1997. Scab of wheat and barley: a re-emerging disease of devastating impact. Plant Dis. 81:13401348.

28. Miller, J. D., Culley, J., Fraser, K., Hubbard, S., Meloche, F., Ouellet, T., Seaman, W. L., Seifert, K. A., Turkington, K., and Voldeng, H. 1998. Effect of tillage practice on Fusarium head blight of wheat. Can. J. Plant Pathol. 20:95-103.

29. Nita, M., De Wolf, E., Madden, L., Paul, P., Shaner, G., Adhikari, T., Ali, S. Stein, J., and Osborne, L. 2006. Effect of corn residue level on disease intensity of Fusarium head blight (FHB) and on deoxynivalenol (DON) concentration: a multi-state field study. (Abstr.) Phytopathology 96:S85.

30. NRCS. Undated. Estimating crop residue cover. Agronomy Tech Note Number MN-19. National Resources Conservation Service, St. Paul, MN

31. Parry, D. W., Jenkinson, P., and McLeod, L. 1995. Fusarium ear blight (scab) in small grain cereals-a review. Plant Pathol. 44:207-238.

32. Paulitz, T. C. 1996. Diurnal release of ascospores by Gibberella zeae in inoculated wheat plots. Plant Dis. 80:674-678.

33. Pestka, J. J. 2007. Deoxynivalenol: toxicity, mechanisms and animal health risks. Anim. Feed Sci. Technol. 137:283-298.

34. Pestka, J. J. 2010. Deoxynivalenol: mechanisms of action, human exposure, and toxicological relevance. Arch. Toxicol. 84:663-679.

35. Pestka, J. J, and Smolinski, A. T. 2005. Deoxynivalenol: toxicology and potential effects on humans. J. Toxicol. Environ. Health B Crit. Rev. 8:3969.

36. Schmale, D. G., III, Leslie, J. F., Zeller, K. A., Saleh, A. A., Shields, E. J., and Bergstrom, G. C. 2006. Genetic structure of atmospheric populations of Gibberella zeae. Phytopathology 96:1021-1026.

37. Shaner, G. 2003. Epidemiology of Fusarium head blight of small grain cereals in North America. Pages 84-119 in: Fusarium Head Blight of Wheat and Barley. K. J. Leonard and W. R. Bushnell, eds. American Phytopathological Society, St. Paul, MN.

38. Stack, R. W. 1997. Gradients of Fusarium head blight in wheat along transects away from a concentrated source of Gibberella zeae ascospore inoculum. Page 60 in Proc. Natl. Fusarium Head Blight Forum, St. Paul, MN

39. Stein, J. M., Osborne, L. E., Bondalapati, K. D., Glover, K. D., and Nelson, C. A. 2009. Fusarium head blight severity and deoxynivalenol concentration in wheat in response to Gibberella zeae inoculum concentration. Phytopathology 99:759-764.

40. Sutton, J. C. 1982. Epidemiology of wheat head blight and maize ear rot caused by Fusarium graminearum. Can. J. Pathol. 4:195-209.

41. Thomason, W. E., Alley, M. M., Stromberg, E. L., Hagood, E. S., and Herbert, A. 2009. No-tillage small grain production in Virginia. Va. Coop. Ext. 424-005.

42. Vos, P., Hogers, R., Bleeker, M., Reijans, M., van de Lee, T., Hornes, M., Frijters, A., Pot, J., Peleman, J., Kuiper, M., and Zabeau, M. 1995. AFLP: a new technique for DNA fingerprinting. Nucleic Acids Res. 23:4407-4414.

43. Windels, C. E. 2000. Economic and social impacts of Fusarium head blight: changing farms and rural communities in the northern Great Plains. Phytopathology 90:17-21 